\title{
Ornithine decarboxylase as a marker for premalignancy in the stomach
}

\author{
S E Patchett, E M Alstead, L Butruk, K Przytulski, M J G Farthing
}

\begin{abstract}
Assessment of mucosal ornithine decarboxylase (ODC) activity in the human large bowel may be of value as a marker of potential malignant risk. Its value as a marker of premalignancy in the upper gastrointestinal tract is less clear. Using a $\left[{ }^{14} \mathrm{C}\right]$-ornithine bioassay, gastric mucosal ODC activity was measured in 32 normal subjects and 22 patients with confirmed gastric cancer. These results were compared with 47 patients at increased risk of upper gastrointestinal malignancy, (32 patients with partial gastric resection, 15 patients with familial adenomatous polyposis). Median ODC activity in normal subjects was $371 \mathrm{pmol} / \mathrm{mg}$ protein/h, (interquartile range (IQR), 230-617). There was no variation with age or sex and no relation to Helicobacter pylori status. Normal subjects had significantly lower ODC activity than patients with a gastric resection or confirmed gastric cancer, but similar to patients with familial adenomatous polyposis. Furthermore, no difference in activity was identified between patients with a gastric resection and established gastric cancer. ODC activity was, however, significantly increased in areas of gastric atrophy or intestinal metaplasia, regardless of the clinical group from which the samples were obtained. It is concluded that measurement of mucosal ODC activity does not provide additional predictive information of malignant risk in the stomach and investigation of other potential biomarkers of malignancy is warranted.

(Gut 1995; 37: 13-16)
\end{abstract}

Keywords: ornithine decarboxylase, malignant risk, stomach.

Increased epithelial cell proliferation occurs in diseases predisposing to gastrointestinal cancer. This is often accompanied by changes in differentiation, identifiable immunochemically or by cloned DNA probes. ${ }^{1}$ Biochemical markers of premalignancy have been sought but none have been shown to antedate the appearance of cytological or histological changes in gut epithelium. ${ }^{2}$ Genetic markers have been reported to be indicators of phenotypic expression of a genetic trait in patients at high risk of colon cancer. ${ }^{3-6}$ These markers seem to be more useful in genetic cancer syndromes and in colorectal cancer than in sporadic upper gastrointestinal cancers. Gastric cancer is an important cause of death in the United Kingdom, with over 10000 related deaths reported in 1988. Evidence from Japan suggests that the early diagnosis of gastric cancer greatly improves the prognosis, with a $96 \%$ five year survival compared with $2 \%$ in advanced disease. ${ }^{7}$ In the United Kingdom, few cases of early gastric cancer are diagnosed endoscopically. ${ }^{8}$ There is little information about detecting people at increased risk of developing upper gastrointestinal malignancy although there are a number of conditions that are known to predispose to cancer. These include Barrett's oesophagus, atrophic gastritis, previous gastric surgery, sporadic gastric and duodenal adenomas, familial adenomatous polyposis (FAP), and Peutz-Jegher syndromes.

Ornithine decarboxylase (ODC) activity has been suggested to be a biochemical marker of cellular proliferation. ${ }^{9}$ ODC is a cytoplasmic enzyme, which catalyses the conversion of the polyamine ornithine to putrescine. The polyamines are essential for regulatory functions in protein and nucleic acid synthesis and are thus vital for cell growth and differentiation. Increases in ODC activity may thus reflect an increased rate of macromolecular synthesis during cellular proliferation. Studies in mucosal biopsy specimens from patients with FAP have suggested that ODC is a useful marker for neoplastic potential. ${ }^{10} \mathrm{An}$ increase in ODC activity has been found in the colorectal mucosa in FAP, being comparatively low in morphologically normal mucosa and increasing with the development of adenomas and with dysplasia. Furthermore it was suggested that phenotypically normal relatives of FAP patients who possess the FAP genotype have increased colonic ODC activity, which precedes the development of morphological changes. ${ }^{11}$

Increased ODC activity has also been reported in the morphologically normal mucosa of patients with sporadic colorectal adenomas $^{12}$ and in dysplastic Barrett's oesophageal mucosa. ${ }^{13}$ No studies on human gastric premalignant conditions have been reported. In this study, we have measured the ODC activity in the upper gastrointestinal tract in normal subjects, subjects at risk of gastric cancer, and patients with established gastric tumours, to assess its value as a potential biomarker of cancer risk.

\section{Methods}

One hundred and three consecutive patients coming to gastroscopy for clinical indications who fulfilled the diagnostic criteria were included in the study. Endoscopic findings
Correspondence to: Bartholomew's Hospital West Smithfield, London EC1A 7BE.

Accepted for publication 24 October 1994 
TABLE I Patient details

\begin{tabular}{llll}
\hline & Number & $\begin{array}{l}\text { Age }(y) \\
\text { median (range) }\end{array}$ & $\begin{array}{l}\text { Male/ } \\
\text { female }\end{array}$ \\
\hline Normal & 32 & $53(23-82)$ & $21 / 11$ \\
Gastric resection & 32 & $61(28-83)$ & $21 / 11$ \\
Gastric cancer & 20 & $73(56-89)$ & $12 / 8$ \\
FAP & 16 & $32(19-52)$ & $10 / 6$ \\
\hline
\end{tabular}

were recorded and biopsy specimens were taken for routine histopathological examination and for the rapid urease test for Helicobacter pylori. In addition two mucosal samples were taken, frozen in liquid nitrogen, and stored at $-70^{\circ} \mathrm{C}$ for the ODC assay. Study groups comprised of 32 subjects with no endoscopic abnormality, 32 patients who had undergone gastric surgery for peptic ulcer disease but with no other endoscopic abnormality, 22 patients with a gastric malignancy at the time of endoscopy, and 15 patients with reported familial adenomatous polyposis. Table I summarises details of these patients. In subjects with normal intact stomachs, mucosal biopsy specimens were obtained from the antrum within $5 \mathrm{~cm}$ from the pylorus. In subjects with malignancy, samples were obtained from endoscopically normal mucosa at least $5 \mathrm{~cm}$ distant from the neoplasm. Specimens from patients with a partial gastrectomy were obtained from normal appearing mucosa at least $5 \mathrm{~cm}$ proximal to the anastomosis. Gastric surgery was carried out for duodenal ulcer disease in $24(75 \%)$ and gastric ulcer disease in $8(25 \%)$. The mean interval from surgery to endoscopy and biopsy was $27 \cdot 8$ years with a range from $2-49$.

Mucosal ODC activity was assayed using a modification of the method described by Beaven et al. ${ }^{14}$ Mucosal specimens were homogenised using an Ultra-Turrac homogeniser in $300 \mu \mathrm{l}$ of buffer containing

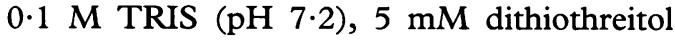
(DTT), and $0.25 \mathrm{mM}$ pyridoxal phosphate. The reaction mixture consisted of $15 \mu \mathrm{l}$ of homogenate, $0.25 \mathrm{mM}$ pyridoxal phosphate, 5 mM DTT with $0 \cdot 15 \mu \mathrm{Ci}$ of $\mathrm{L}-\left[{ }^{14} \mathrm{C}\right]$-ornithine hydrochloride (Amersham International) in a total volume of $30 \mu \mathrm{l}$. The reaction tube was sealed with a rubber cap in which was embedded a $0.5 \times 0.5 \mathrm{~cm}$ square of Whatman no 1 filter paper soaked with $50 \mu l$ methylbenzethonium hydroxide. Tubes were incubated

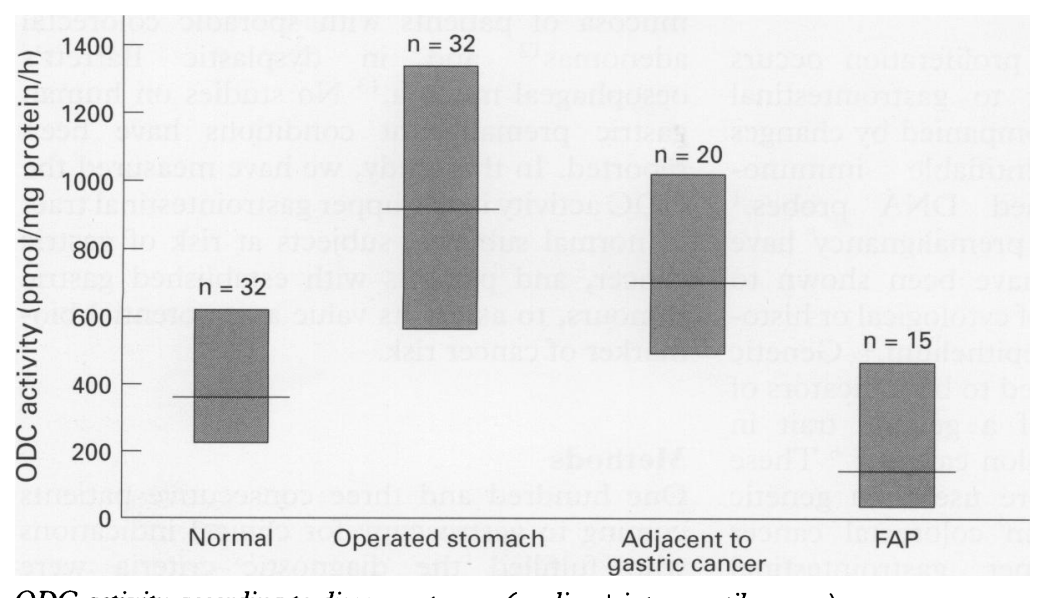

$O D C$ activity according to disease category (median+interquartile range). at $37^{\circ} \mathrm{C}$ for 60 minutes and the reaction then stopped by injecting $100 \mu \mathrm{l} 20 \%$ trichloroacetic acid. After an additional 30 minutes incubation for equilibration, the filter paper was removed and placed into $5 \mathrm{ml}$ of scintillation liquid and counted in LKB Wallac Ultrabeta 1210 scintillation counter. Results were expressed as pmol of $\left[{ }^{14} \mathrm{C}\right] \mathrm{O}_{2}$ released per hour per mg of tissue protein. The protein content of the homogenate was estimated using the bicinchoninic acid micro-titre protein assay (Pierce). All assays were performed in duplicate and included negative controls. Comparison of the ODC activities in the various clinical groups was performed using Wilcoxon's rank sum test for unpaired data or analysis of variance (ANOVA) where appropriate.

\section{Results}

In the gastric mucosa of normal subjects, median ODC activity was $371 \mathrm{pmol} / \mathrm{mg}$ protein/h (interquartile range (IQR), 230-617). No variation with age was identified, and activities for men and women were similar (Table II). Of the 32 subjects with no endoscopic abnormality on endoscopy, 18 were $H$ pylori positive $(56 \%)$ and $14(44 \%)$ were $H$ pylori negative. Of those patients who were $H$ pylori positive, all had evidence of chronic active gastritis, six $(33 \%)$ had gastritis with atrophy and two (11\%) had focal intestinal metaplasia. Patients without $H$ pylori infection had no histological abnormality. No significant difference in ODC activity between $H$ pylori positive patients and $H$ pylori negative patients was noted. ODC activity in gastric mucosa from patients who had undergone gastric surgery was significantly increased compared with normal subjects $(p=0.007)$ although there was some overlap between the two groups (Figure). In common with biopsy specimens from the normal stomach, ODC activity in the operated stomach was not related to age, or sex, and there was no correlation between ODC activity and time between surgery and endoscopic examination $(r=0 \cdot 3$, $\mathrm{p}=\mathrm{NS}$ ). Nine patients had a Billroth 1 gastrectomy, 15 had a Billroth 2 gastrectomy, and eight patients had a vagotomy with a drainage procedure. The type of operation, however, did not influence ODC activity (Table III). The median ODC activity in macroscopically

TABLE II ODC activity in the endoscopically normal stomach

\begin{tabular}{|c|c|c|c|c|}
\hline & \multirow[b]{2}{*}{ Number } & \multicolumn{2}{|c|}{$O D C$ activity } & \multirow[b]{2}{*}{$\stackrel{p}{\text { Value }}$} \\
\hline & & Median & $\begin{array}{l}\text { Interquartile } \\
\text { range }\end{array}$ & \\
\hline \multicolumn{5}{|l|}{ Age } \\
\hline $0-49$ & 13 & 438 & $308-857$ & \\
\hline $50-69$ & 11 & 268 & $117-458$ & \\
\hline $70+$ & 8 & 371 & $267-456$ & $0 \cdot 3$ \\
\hline \multicolumn{5}{|l|}{ Sex } \\
\hline Male & 21 & 268 & $271-742$ & \\
\hline Female & 11 & 384 & $121-477$ & $0 \cdot 7$ \\
\hline \multicolumn{5}{|l|}{$H$ pylori status } \\
\hline Negative & 14 & 279 & $171-438$ & \\
\hline Positive & 18 & 398 & $268-705$ & 0.54 \\
\hline
\end{tabular}

${ }^{\star}$ Wilcoxon rank sum test. 
TABLE III ODC activity in the postoperative stomach

\begin{tabular}{|c|c|c|c|c|}
\hline & \multirow[b]{2}{*}{ Number } & \multicolumn{2}{|c|}{$O D C$ activity } & \multirow[b]{2}{*}{$\stackrel{p}{\text { Value }^{\star}}$} \\
\hline & & Median & $\begin{array}{l}\text { Interquartile } \\
\text { range }\end{array}$ & \\
\hline \multicolumn{5}{|l|}{ Age } \\
\hline $\begin{array}{c}0-55 \\
56-75 \\
75+\end{array}$ & $\begin{array}{l}11 \\
11 \\
10\end{array}$ & $\begin{array}{r}983 \\
664 \\
1137\end{array}$ & $\begin{array}{l}629-1991 \\
125-1325 \\
633-1428\end{array}$ & 0.67 \\
\hline \multicolumn{5}{|l|}{ Sex } \\
\hline Male & 21 & 903 & $459-1372$ & \\
\hline Female & 11 & 983 & $532-1691$ & 0.79 \\
\hline \multicolumn{5}{|l|}{ Operation } \\
\hline Billroth 1 & 9 & 1352 & $983-1372$ & \\
\hline Billroth 2 & 15 & 634 & $198-1372$ & \\
\hline \multicolumn{5}{|l|}{ Vagotomy and } \\
\hline drainage & 8 & 804 & 544-1374 & $0 \cdot 12$ \\
\hline
\end{tabular}

normal mucosa from patients with established gastric cancer was $724 \mathrm{\rho mol} / \mathrm{mg}$ protein/h IQR 469-1068, which was significantly increased compared with healthy controls $(p<0.01)$. However, there was again a considerable overlap with control values. Of note, ODC activity in mucosa adjacent to a carcinoma was not significantly different to that in the postoperative stomach $(p=0 \cdot 1)$ (Figure). Histological findings in the macroscopically normal mucosa were similar in these two groups with no significant difference in the proportion of patients with mucosal atrophy or intestinal metaplasia (Table IV). In both these clinical groups, the presence of atrophy and metaplasia was significantly more common than that in the endoscopically normal group. Furthermore, ODC activity was significantly increased in patients with atrophy or metaplasia irrespective of the underlying clinical disease state. In 13 patients with gastric cancer, ODC activity was simultaneously measured in the tumour tissue and was shown to be significantly higher than any other group (1563 $\mathrm{pmol} / \mathrm{mg}$ protein/h IQR 582-2995).

ODC activity in 15 patients with familial adenomatous polyposis was also similar to healthy controls $(144 \mathrm{pmol} / \mathrm{mg}$ protein/h IQR 23-514). Although endoscopy was macroscopically normal in each of these patients, and thus none of these patients had established gastric adenomatous polyps, histological examination showed evidence of gastric hyperplasia in $80 \%$.

\section{Discussion}

ODC activity is now known to be essential for cell growth and also for malignant transformation. ${ }^{15}$ Polyamine concentrations and ODC activity are increased in rapidly proliferating tissue and several groups have shown increased polyamines and ODC activity in colonic mucosa at risk of malignancy. ${ }^{16} 17$ The potential value of ODC as a diagnostic marker of an

TABLE IV Relations of histology and ODC activity to clinical groups

\begin{tabular}{lccc}
\hline & Normal/gastritis & Atrophy & Metaplasia \\
\hline Total (number) & 42 & 26 & 16 \\
Normal & 24 & 6 & 2 \\
Postoperative stomach & 10 & 14 & 8 \\
Adjacent to cancer & 8 & 6 & 6 \\
ODC activity & 371 & 891 & 951 \\
Median & $203-705$ & $477-1372$ & $644-1348$ \\
IQR & & &
\end{tabular}

abnormal proliferative state in FAP has been suggested by Luk and Baylin. ${ }^{11}$ The increased ODC activity found in dysplastic Barrett's epithelium suggests that ODC may also be a useful marker for upper gastrointestinal tract malignancy. ${ }^{13}$ More recently, however, the value of ODC measurement as a marker for sporadic colonic malignancy has been questioned principally because of the considerable overlap between normal and 'at risk' mucosal ODC activities. ${ }^{18} 19$

In this study we have examined the value of ODC activity as a potential marker for malignant risk in the stomach by comparing ODC activity in the normal stomach, in conditions known to predispose to upper gastrointestinal malignancy, and in stomachs with a concomitant gastric malignancy. In the normal stomach, the range of ODC activities is comparatively wide and in contrast with some previous reports, we have not found any relation to age or sex. ${ }^{20}$ The presence of $H$ pylori, which is inevitably associated with chronic active gastritis and may play a part in the genesis of gastric cancer ${ }^{2122}$ was also not found to influence ODC activity. This is in contrast with preliminary data, which suggests that mucosal proliferation assessed by immunohistochemical techniques may be increased by $H$ pylori colonisation. ${ }^{23}$ As a group, patients with an operated stomach had a significantly higher ODC activity compared with normal controls, regardless of the nature of the gastric operation although there was some overlap between this group and controls. Perhaps most important, however, was the inability of ODC measurements to differentiate between patients at risk of gastric cancer, such as patients after gastric resection and patients with an established gastric cancer. Although ODC activity in both groups was greater than in controls, they were not significantly different from each other. This may in part be explained by the histological similarity of the macroscopically normal mucosa in these two groups. The presence of atrophy or metaplasia is associated with significantly higher ODC activity regardless of whether the specimen was from the postoperative stomach or from an area adjacent to a tumour. Neither ODC activity or histological examination from normal adjacent mucosa, however, could differentiate biopsy specimens from the postoperative stomach or a tumour bearing stomach. Furthermore, ODC activity in the stomach of patients with FAP, who are known to be at risk of upper gastrointestinal malignancy ${ }^{24}$ and who also commonly display histological abnormalities such as microadenoma formation were no different to control subjects. Thus the known increased malignant risk of this group of patients was not mirrored by an increase of ODC activity. The finding of a relation of ODC activity to defined histological abnormalities is interesting though unlikely to be useful clinically, as it is in the absence of definable morphological abnormalities that potential biomarkers of malignancy are likely to be of greatest value.

Initial studies on ODC activity in human gut tissue were extremely encouraging, suggesting 
that this comparatively simple bioassay could provide an accurate indicator of malignant potential, particularly in histologically normal tissue. ${ }^{10}$ Furthermore, it has been suggested that ODC activity could differentiate patients at increased genetic risk of colon cancer but with normal colons, from those at low risk. ${ }^{11}$ More recent studies of ODC activity in the large bowel have been less encouraging. Two recent studies have shown that the measurement of ODC activity was unable to differentiate patients with adenomatous polyps from normal subjects and was thus a poor indicator of cancer risk. ${ }^{18} 19$ Variations in technique and expertise between laboratories may partly explain these anomalies though, even laboratories with considerable experience find considerable overlaps between groups. The handling and storage of tissues is felt to be an important factor in the observed variability but in this study all tissue was flash frozen and stored at $-70^{\circ} \mathrm{C}$. In addition all assays were performed within three weeks of tissue collection.

In summary, we have identified differences in gastric mucosal ODC activity between controls and certain disease states. We did not show any difference, however, in ODC activity between controls and patients with familial polyposis, or between patients with an operated stomach and those with a gastric tumour. Specific histological abnormalities such as atrophy and intestinal metaplasia are associated with increased polyamine biosynthetic activity but this is not specifically related to the clinical disease state. The inability to differentiate groups at risk of gastric malignancy from those with established cancer suggests that measurement of polyamine biosynthetic activity will probably not be a valuable clinical marker of increased cancer risk.

S E Patchett gratefully acknowledges the support of the Joint Research Board, St Bartholomew's Hospital.

1 Okamoto M, Sasaki M, Sugio K, et al. Loss of constitutional heterozygosity in colon carcinoma from patients with familial polyposis coli. Nature 1988; 331: 273-7.

2 Lipkin M. Biomarkers for increased susceptibility to gastrointestinal cancer. Their development and application to studies of cancer prevention. Gastroenterology : 1083-6.

3 Quirke P, Dixon MF, Day DW, Fozard JBJ, Talbot IC, Bird
CC. DNA aneuploidy and cell proliferation in familial adenomatous polyposis. Gut 1988; 29: 603-7.

4 Bodmer WF, Bailey CT, Bodmer J, et al. Localisation of the gene for familial adenomatous polyposis on chromosome 5. Nature 1987; 328: 614-6.

5 Cannon-Albright LA, Skolnick MH, Bishop T, et al. Common inheritance of susceptibility to colonic adenomatous polyps and associated colorectal cancers. $N$ Engl $\mathcal{F}$ Med 1988; 319: 533-7.

6 Vogelstein B, Fearon ER, Hamilton SR, et al. Genetic alterations during colorectal-tumour development. $N$ Engl $\mathcal{f}$ ations during colorectal-

7 Williams GT. Early gastric cancer. In: Filipe MI, Jass JR. Gastric carcinoma. Edinburgh: Churchill Livingstone, 1986: 172-96.

8 de Dombal FT, Price AB, Thompson H, Williams GT, Morgan ACI, Softley A, et al. The British Society of Gastroenterology early gastric cancer/dysplasia survey: an interim report. Gut 1990; 31: 115-20.

9 Boutwell RK. Evidence that an elevated level of ornithine decarboxylase activity is an essential component of
tumour promotion. Adv Polyamine Res 1983; 4: 127-33.

10 Luk GD, Silverman AL, Giardiaello FM. Biochemical markers in patients with familial colonic neoplasia. Semin markers in patients with fam

11 Luk GD, Baylin SB. Ornithine decarboxylase as a biological marker in familial colonic polyposis. N Engl f Med 1984; 311: $80-3$.

12 Narishawa T, Takahashi M, Niwa $M$, H Koyama, Kotanagi $\mathrm{H}$, Kusaka $\mathrm{N}$, et al. Increased mucosal ornithine decarboxylase activity in large bowel with multiple tumours, adenocarcinoma and adenoma. Cancer 1989; 63: 1572-6.

13 Garewell HS, Sampliner R, Alberts D, Steinbronn K. Increase in ornithine decarboxylase activity associated with the development of dysplasia in Barrett's oesophagus. Dig Dis Sci 1989; 34: 312-4.

14 Beaven MA, Wilcox G, Terpstra GK. A microprocedure for the measurement of ${ }^{14} \mathrm{CO}_{2}$ release from $\left[{ }^{14} \mathrm{C}\right]$ carboxylthe measurement of $\mathrm{CO}_{2}$ release from $\left[{ }^{14} \mathrm{C}\right]$ carboxyl-

15 Auvinen M, Paasinen A, Andersson LC, Hölttä E. Ornithine decarboxylase activity is critical for cell transformation. Nature $1992 ; 360 ; 355-8$

16 Arlow FL, Colarian J, Calzada R, Luk GD. Differential activation of ornithine decarboxylase and tyrosine kinase in the rectal mucosa of patients with hyperplastic and adenomatous polyps. Gastroenterology 1991; 100: 1528-32. 17 Porter CW, Herrera-Ornelas L, Pera P, Petrelli NF, and neoplastic human colorectal tissue. Cancer 1987; 60: 1275-81.

18 Desai TK, Parikh N, Bronstein JC, Luk GD, Bull AW. Failure of rectal ornithine decarboxylase to identify adeno-
matous polyp status. Gastroenterology 1992; 1103: 1562-7.

19 Sandler RS, Ulshen MH, Lyles CM, McAuliffe CA, Fuller CR. Rectal mucosal ornithine decarboxylase activity is not a useful marker of risk for colorectal neoplasia. Dig Dis $S_{c i}$ 1992; 37: 1718-24.

20 Fireman Z, Rozen P, Fine N, Chetrit A. Influence of dermographic parameters on rectal epithelial proliferation. Cancer Lett 1989; 47: 133-40.

21 Parsonnet J, Friedman GD, Vandersteen DP, et al. Helicobacter pylori infection and the risk of gastric carcinoma. N Engl F Med 1991; 325: 1127-31.

22 Nomura A, Stemmermann GN, Chyou P, et al. Helicobacter pylori infection and gastric carcinoma among Japanese Americans in Hawaii. $N$ Engl $\mathcal{f} \mathrm{Med}$ 1991; 325: 1132-6.

23 Lynch DAF, Clarke AMT, Jackson P, Dixon MF, Quirke P, Axon ATR. Cell proliferation in H pylori associated gas-
tritis and the effect of eradication therapy. Gut 1993; 34 (ruppl 1): S3.

24 Jangelmaan DG, Decosse J, Bussey HJ. Upper gastrointestinal cancer in familial adenomatous polyposis. Lancet 1988; 1: 1149-51. 